\title{
Authenticity, Reception and Media Reality
}

\section{Abstract}

Peter Jan Kosmály

This article deals with the reception of media reality, which is meant to be an alternative mode of consciousness, and with the phenomenon of authenticity and its understanding within media reality. It is also pointed out the distortion in the reception of media reality. As an unifying concept for media education and for the treatment of reception defects it is mentioned media anthropology - an interdisciplinary, respectively trans-disciplinary science, which can provide more consistent re-analyzing of the relationship between man and media as tools for improving his skills. From the methodological point of view the method of epistemological anarchism, Paul Feyerabend's "anything goes" is explained as an epistemological translation tool for developing reviewing competences and reception skills as a whole (organic reception). We propose to deal the distortion of media reception in different therapeutic ways: from sensory deprivation, through media substitution, organic reception, to transcendence of the observer and imitation of media - meta-creation. In the sense of organic, systemic reception we in fact propose to "copy" the communication strategy of media system(s) in order to extend or set appropriate "epistemic" competences. In the related illustration of this mechanism, the theory of A. Weinstock is applied for setting a research indifference point in the middle of a fictive reception continuum of polarities sympathy and antipathy with media. This paper represents a part of activities, which summarize author's dissertation thesis Reception instruction in the media reality, where there are presented not only analyses and attempted typology of reception instructions, but also case studies with specific proposals for teaching and researching within areas of media ethics and media education.

Keywords: | reception, media reality, authenticity, critics, ethics, hyperreality

JEL Classification: M30, I20, I23, L15, L80, L81, L82

\section{Introduction}

This study on authenticity and media reality begins with some explained paradoxes and will end with a conclusion - an instruction, a recipe how to treat the reception in media reality. As the first paradox the light pollution is mentioned, which can be obviously "visualized" in a map, semiological and media-anthropological artifact (see e. g. NASA's project Visible Earth and images of Earth cities lights or The first World Atlas of the artificial night sky brightness). 
Within the debate about media philosophy there can be raised a question, why is something as illogical as pollution produced and not exploited - why isn't light "harvested" and used, but in fact there are billions of electric sodium or halogen or neon bulbs thorough the whole word shining every night up to sky and from Earth to space? There are millions of "lit shops", which are actually closed: in fact their brands are re-presented through every night into the "face of the earth in space". And as well as this question may sound anarchistic or provocative, so is the answer. The media discourse knows a media theory based on the theory of information. It is The Mathematical Theory of Communication published in 1949 by Claude Shannon and Warren Weaver. Principally, this theory is responsible for the definition of information as a reduction of entropy, following Ludwig Boltzmann and others (Shannon - Weaver, 1964a, p. 3), a reduction of infinity. But many years after 1949 the information overload or semiological pollution (Heilbrunn, 1996, p. 111) are counted among very essential of the current period of human being (however, the term is discussed, see Merlyn, 2008). So, if there exists a pollution, it means the opposite of entropy and this redundancy defines "the new information" - or we may say, that the information created as reduction of entropy is represented through information created within redundancy and a need for entropy - having no value, only binary status "reproduced" (1) or "not used" (0). So the emergence of this "new information" is as itself pure information, but the content becomes media - it carries a message and a reception instruction or a reception frame.

Figure 1 The Light Tourine Shroud of current civilization - an inverted imprint of artificial light pollution of Earths inhabitants to space

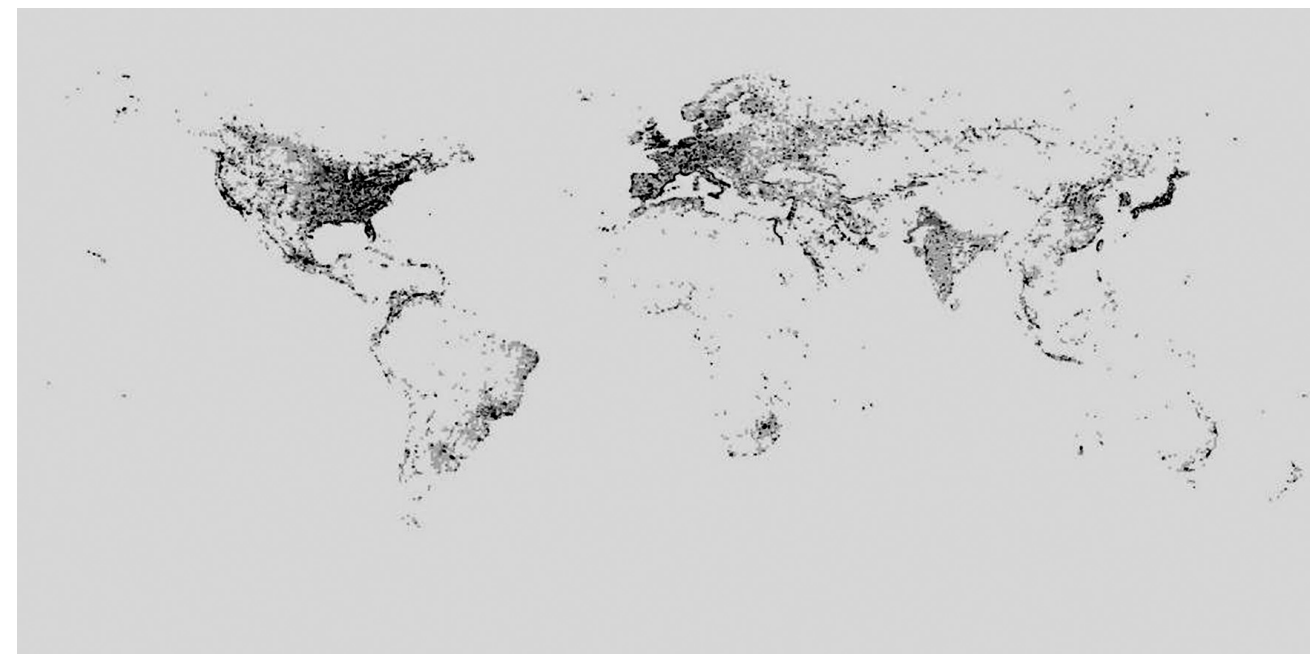

Source: http://eoimages.gsfc.nasa.gov/images/imagerecords/55000/55167/earth_lights.gif, picture re-designed by author of this study

Because of this semiological "second-hand signification" (exnomination) the pollution in media reality is so important - in creates entropy, the necessary entropy to produce such information; information characterized not as signs, but already as simulacra... Their redundancy is almost the whole system, as it is included in such a super-sign or hyperreal simulacrum as a reception frame. Warren Weaver used in his part of The Mathematical Theory of Communication more philosophical, instructive and explanatory language, so he describes also a category - freedom of choice: "That 
information be measured by entropy is, after all, natural when we remember that information, in communication theory, is associated with the amount of freedom of choice we have in constructing messages..." (Shannon - Weaver, 1964b, p. 13). Other classical communication theory elements include the code - alphabet, which has to be the same, and the opposite for (relative - maximum) entropy is redundancy. Claude Shannon already in 1949 calculated the redundancy of ordinary English among words with distance no greater than eight letters as "roughly 50\%" and noticed that "when we write English half of what we write is determined by the structure of the language and half is chosen freely." (Shannon - Weaver, 1964c, p. 56). This ratio of the element "redundancy" in a language is an epistemic anarchism based one in sense of "anything goes" method and "anything exists" principle as constitutional blocks of science, knowledge and language or society as objects of such a (free) science. However, Shannon described three methods which gave him the approximate result of $50 \%$ redundancy in English: "One is by calculation of the entropy of the approximations to English. A second method is to delete a certain fraction of the letters from a sample of English text and then let someone attempt to restore them. If they can be restored when 50\% are deleted the redundancy must be greater than 50\%. A third method depends on certain known results in cryptography..." (Shannon - Weaver, 1964d, p. 56). In further explanation he uses metaphorical model of a crossword puzzle that represents dimensions related to redundancy. For example, if "the redundancy is zero any sequence of letters is a reasonable text in the language and any two-dimensional array of letters forms a crossword puzzle." (Shannon - Weaver, 1964e, p. 56). If there would be a complete freedom (entropy), redundancy would be low and "everything would go" - every group of letters would probably have certain meaning. The appropriate redundancy for codable and decodable communication languages is according to Shannon $50 \%$ - so is the freedom of communicator's choice as the ratio for possibility of new information - which decreases entropy. Weaver notices in his part, that if language "has only 20 per cent of freedom, then it would be impossible to construct crossword puzzles in such complexity and number as would make the game popular." (Shannon - Weaver, 1964f, p. 14) and Shannon informs in his part, that "If the redundancy is 33\%, three-dimensional crossword puzzles should be possible, etc." (Shannon - Weaver, 1964g, p. 56-57). And with the notion to media anthropological focus and the "light" introduction of this study a question could be raised, that may sound paradoxically: Is it possible to count minimum how many supermarkets have to be "lit" to produce the first "reverted" information - to initiate the process of exnomination? Also brilliant and recognized researchers as Claude Shannon and Warren Weaver obey the "paradox on linguistic neutral" - research of language and media reality, media systems have to use a meta-language, but the researcher is not able to be in a neutral and position and to describe language without language - it would not be allowed to call it a science then. But sometimes a solution to paradoxes is to unite them across their representations in order to form a new inquiry, task or research or to re-formulate and correct the actual one. So the new information, which emerges apart from system regulations (if they are broad, the redundancy - number of unnecessary system events - will be high, if they are tight, the redundancy number will be low) has to have its value based at probability of its emergence - at the level of communicator's freedom to formulate the information, which can be high (the ratio between relativity and reality is in favor of emergence) or low (reduction the entropy isn't probable, unnecessary events occur often). The topic of metalanguage - that reduces the entropy of system events and produces information occurs in Shannon, Weaver's work in this poetic formulation: “...entropy not only speaks 
the language of arithmetic; it also speaks the language of language." (Shannon - Weaver, 1964h, p. 28). This may show how Shannon and Weaver used their metalanguage to describe their object of research. But a universal, appropriate answer to the paradox of linguistic neutral was given by Stuart Hall as he described relations between the discourse (theory) and the object: "...it is the discourse which constitutes the subject position of the social agent, and not, therefore, the social agent which is the origin of the discourse - the same system of rules that makes the spherical object into a football, makes me the player. The existence of objects is independent of their discursive articulation..." (Hall et al., 1997, p.70). This is a crucial thesis also for media education, as every education needs besides its discourse and theory also an epistemic translation (teacher has to explain not only, what object means, but also how to describe it). In media history and media education there was no "zero generation". There was no generation of people using media through their whole life and then in the stage of transfer of knowledge educating about media their descendants and so on... We are educated about media from people which experienced written communication and had no idea about a mobile or internet communication some years ago and on the other hand we can experience young recipients wholly raised in the world of media or within media reality, which provide beneficial insights as well. To sum up the "light paradox" outlined in this introduction, it could be noticed, that light was once information, in times when it reduced the infinity of dark, but nowadays it is a medium and transfers a message - a reception frame. This thesis allows us not only to identity light (media) abuse or other reception deformations, but also to treat reception deformations in order to achieve organic - whole and systemic reception. And an example is provided also by the "light phenomenon", in a study by Erin M. Craine on Preliminary Experiments Using a Digital Camera to Measure Commercial Light Sources. Craine describes experiments with researching the light pollution and using available digital camera, so that almost every member of a certain society (e.g. media anthropologists) would be equipped a epistemically educated to lead on own research: "Interest in these measurements is a consequence of our desire to learn more about techniques and methods for defining, measuring, and characterizing glare associated with various light sources. With development of a successful protocol, International Dark Sky Association (IDA) members should be able to collect large numbers of images of geographically distributed light sources that can be measured for brightness, as well as evaluated for glare. Experience with such a protocol is described in this report." (Craine, Erin M. Preliminary Experiments Using a Digital Camera to Measure Commercial Light Sources. p. 1, available online). Because, as was written in previous lines, a reception instruction is formed with the medium as well, as a part of the message, and it may be a research problem to identify (either based on entropy and redundancy or on other method) information part of the message and the reception instruction. For the light pollution map simulacrum, there is a reception instruction formulated within the text describing the project Earth's City Lights. The text - an official release from NASA organization - ends sentences, where there is invention of light and the dark put together in a relation of polarities - light is favored as the symbol for populated, urbanized, areas: "Even more than 100 years after the invention of the electric light, some regions remain thinly populated and unlit. Antarctica is entirely dark. The interior jungles of Africa and South America are mostly dark, but lights are beginning to appear there. Deserts in Africa, Arabia, Australia, Mongolia, and the United States are poorly lit as well (except along the coast), along with the boreal forests of Canada and Russia, and the great mountains of the Himalaya." (Earth’s City Lights, available online). 
In following lines, there will be described how can a new methodology for researching media systems and media reality allow all the theories to compete at the same field of human and media, preciously like than it already happens in media realities.

\section{Media as a living system}

After 100 years of Mass Age the demarcation lines between certain theories concerning the study and research of language were yet not vanished and there are still scientists, which do not include media communication into their study of language.

Communication, however, can't be explained only as a simple linear transfer from the left side (the creator) to the right side (recipient); during one hundred years mass media communication has turned into a phenomenon, an evolution degree of human consciousness and knowledge and it is an accelerator of itself and innovator of human capabilities. The seemingly trivial statement in the preceding lines can be developed into the comparison between researchers of media reality, as there will be a difference between linguist and literary scientist and media anthropologist. Umberto Eco in 1987 criticized McLuhan's thesis, confronted them with Jakobson's communication model and stated that McLuhan's media phenomena sometimes reflect Jakobson's elements function of the channel or the code or the shape of the message. This criticism significantly expresses the understanding of communication in separate worlds of two scientists - none of them considers his vision of the world as illusory or distorted. The boundaries between a literature and linguistics researcher and a mass media communication researcher are clearly influences at least by two fundamental facts, two phenomena: timelessness - in classical linguistics and literary studies are phenomena which can't be clearly attributed with a (given) a timeline called gnomonic, but in mass media communication is the "timeless" aspect, as a violation of natural human communication, a key aspect; and the position of the researcher - classical linguist and literary scientist can't within their research of mass media communication depart from their position of researcher and from their knowledge and theories, but in mass media communication often all recipients have the same value - zero (inactive) or one (active). In the mass media communication research there is therefore necessary to consider many phenomena. With regards to the model of the system, in this paper we will develop the concept of creation and reception described by Anton Popovič and František Miko in the book The Creation and The Reception. According to their theory the reception instruction is a function of creation and metacreation and as itself the reception instruction is rather a phenomenon than a plain category. In this sense it is possible to comment Eco's remarks so, that in media reality (system) the "form of content" and the "form of media" may differ and should be distinguished. Roderick Munday in his study gives an example of J. Joyce's literary style, which in his work gained many forms of content, but used only one form of medium, Joyce published books. Munday therefore develops McLuhan's thesis to identify the media system, media reality and its effect on humans: "The medium is the message, because media creates its own environments, which are beneficial to some messages whilst being hostile to others. Just as sodium-vapour light mutes all colours to an orangey-grey and ultra-violet light makes white and some colours glow eerily, so different media amplify and repress their content. If some people lived in a world constantly illuminated by sodium vapour light, they would have very different perceptions of reality compared with people who lived in a world illuminated only by ultra-violet light, although the people of both worlds would be unaware of any distortion in their vision. " (Munday, 2003, available online). This briefly 
explains also the point of view used in the introduction of this study - the light has created a light reality, the media environment with all the events and phenomena included. The system and functions of certain parts concerning media reality could be well described with a theory outstanding from Popovič's functional description of the literary system and Miko's description of expressive stylistics as a methodology. Popovič outlined a literary system with specific genres - the system of literary communication, the system of literary knowledge and other subsystems (media reality also includes communication systems using forms - genres) and specific phenomena: e. g. the system of literary knowledge has three functions: substitute the original for reading purposes, to be a reception instruction and to persuade reader about qualities of the literary work (Miko - Popovič, 1978, p. 304). Additionally, the reception instruction takes three function of literary knowledge - to inform the indifferent reader about ideological and esthetical features of the literary work, it provides instructions for reception and tries to encourage or discourage the reader from reciped work (Popovič et al., 1983, p. 156). Abstracting from literary system and literary reality to media reality - with media defined as extensions of man - we may not only research reception instructions in media reality, but also consider the whole system of myth production as what was in Miko's and Popovič's work described as the system of literary knowledge (Miko - Popovič, 1978). So functions of reception instruction in media reality will remain "to substitute original or instruct about its qualities, to transfer knowledge and instructions for use, to persuade about certain reception frame". Myth production is considered a sub-system of the (mass) media communication system and in media reality it is responsible for distribution on knowledge (ideology). But for the search for freedom within media reality is inevitably associated with the recognition of media reality as an alternative mode of consciousness, operated by the media system (within the media discourse - media thinking); and with the ability to de-link from this system (deconstruct and understand it). Otherwise there may be reception distorted and re-constructed into a Narcis similar stiffness, fascination and finally amputation (described in McLuhan's philosophy) with results in human consciousness and the result in recipients as perfect machines, whose bodies as well as thinking are "externalized" (cyborgs) - so for maintenance of their bodies individual must not develop any activity, because the system takes all the care; this is the "logic" (discourse), which can be found in many reception instructions in media reality. If the legendary Hitchhiker's Guide to the Galaxy - a fictive book explained in a book - as a form of media reception followed by media production begins with words "Don't panic", the Hitchhiker's Guide to the Media Reality, a book born as a metaphor of a fictive book explained in a form of reception instruction, could begin with the same and add: "Anything goes".

\section{Related metaphysics and methodology, epistemic translation tool}

In the sense of relations between creation - reception - receptional metacreation, which were described by F. Miko and A. Popovič, the process of reception should end in a receptional metacreation and production. In media reality it should exist a more epistemic response than a receptional metatext in the system of literary knowledge moreover it should serve as a mental tool, translating mechanism and the process of media reception should then lead to media production. "Epistemic" we mean in the sense of social heritage/knowledge distribution, in the sense of revealing elementary constituting bricks of communication, system, reality, etc. Already in Popovič`s and 
Miko's work was explained a genre, whose elementary function is to orientate. As a genre, review operates within the literary system - in the system of production of literary knowledge (as shown by A. Popovič and F. Miko); it is a mechanism of classification and orientation, the first step of reception successfully ending in production (receptional metacreation). Such epistemic tool is as simple as the dialogue between the priest and the farmer about Slovak cultural institution found in Daniel Lichard's work and as instrumental as glasses - goggles - which misled the Pilgrim in Komensky's work Labyrinth of the World and Paradise of the Heart (Labyrint světa a ráj srdce). The idea of the instrument is to review - give one's opinion, even more a reception instruction or whole receptional frame. And the only one tool dealing with hyper-reality - based on irregulative and unpredictable relations as hyperreality itself - a methodological (or better said, trans-methodological) principle for reviewing media reality is the principle "anything goes". If this principle would serve media-anthropological based reviews of media reality, it could teach us to control and to liberate reception of reality in order to passively respond in form of affirmation. "It is clear, the, that the idea of a fixed method, or of a fixed theory of rationality, rests on too naive a view of man and his social surroundings. To those who look at the rich material provided by history, and who are not intent on impoverishing it in order to please their lower instincts, their craving for intellectual security in the form of clarity, precision, ,objectivity', ,truth', it will become clear that there is only one principle that can be defended under all circumstances and in all stages of human development. It is the principle: anything goes." (Feyerabend, 1993, p. 19) These are words written by a philosopher from the 1960's, Paul Feyerabend, famous for, sometimes pejoratively marked as "trendy" epistemological anarchism. Epistemological anarchism is in a quest for something (nowadays, e.g. in quantum physic the actual "trendy" quest is for the "God Particle", The Higgs Boson) that can instrumentally serve to analyze, to "science" the object. And for Feyerabend this was not a question of a linguistic component or a frame or other social/political constellations, nor a question of scientific revolutions (Thomas Kuhn), it was more a question of a guiding principle securing the scientist through his journey into the deep of unknown. Nor is true that Feyerabend was against science or even tried to relativize it. He was, actually, one of the pioneers objecting that a relation between human and its media (incl. language and ideology) is tight, but dense and can be tracked vice versa. The reason for adding him to prophets of media anthropology can be justified from this quotation, where he explains his intention - in fact to humanize "sciencing": "I therefore again warn the reader that I don't have the intention of replacing 'old and dogmatic' principles by 'new and more libertarian ones '. For example, I am neither a populist for whom an appeal to 'the people' is the basis of all knowledge, nor a relativist, for whom there are no 'truths as such' but only truths for this or that group and/or individual. All I say is that non-experts often know more than experts and should therefore be consulted and that prophets of truth (including those who use arguments) more often than not are carried along by a vision that clashes with the very events the vision is supposed to be exploring." (Feyerabend, 1993, p. XIII Preface to The Third Edition) This once more focuses on the paradox, that within media reality experts and consumers and their reception have the same value and a reception competences should therefore not be built gradually - from beginner to an expert - it should more suit the concrete recipient and have various forms (e.g. from substitution to media metacreation). The method "anything goes" is an essence of every system - as we scientifically call "natural or artificial compositions of parts or members" and it was also used to establish systemic research in its beginnings, because every possible event can 
play a role in system - the same "argument" was used structuralism, semiotics, phenomenology and hermeneutics as well - in the period when these sciences had to legitimize themselves as relevant for "sciencing" their objects. Feyerabend explained the role of "anything goes". Problem is, that an "argument" from observation is misleadingly connected with the ideology and cannot therefore be "real", it only could made be real and could not be a methodological tool. Therefore the method "anything goes" as an argument from observation has to be epistemically translated into an instruction for reviewing media reality as a more dimensional reception mechanism. In following lines there is the model of organic reception described with the help of second step signification mechanism called by R. Barthes exnomination (two triangles) and the mechanism of transcendence of polarities explained by A.Weinstock (sw. Adjaya). In the model of organic reception, the role of "anything goes" principle is to stand for Indifference element - the constitutional element of receptional reaction considering pros and cons (or positive, negative feedback). Adjaya explained indifference as following the indifferent middle point for example in the continuum with sympathy and antipathy (aversion) as two poles (Ajaya, 2000, p. 159). Indifference is therefore limited as it does not cover sympathy and antipathy, but as indifference isn't the goal, only a tool, "anything goes" stands for "everything is usable, quotable” and indifference point stops to be a middle between two polarities, it will act as the third apex of the triangle. Indifferent "anything goes" statement based on observation of both poles will turn itself into a construction mechanism of receptional metacreation, so the center of balance is experiences and understanding of the whole. The organic reception could be illustrated as in Figure 2.

Figure 2 The system of organic reception and applying "anything goes" principle as indifference and as an element for conation with the goal "understanding"
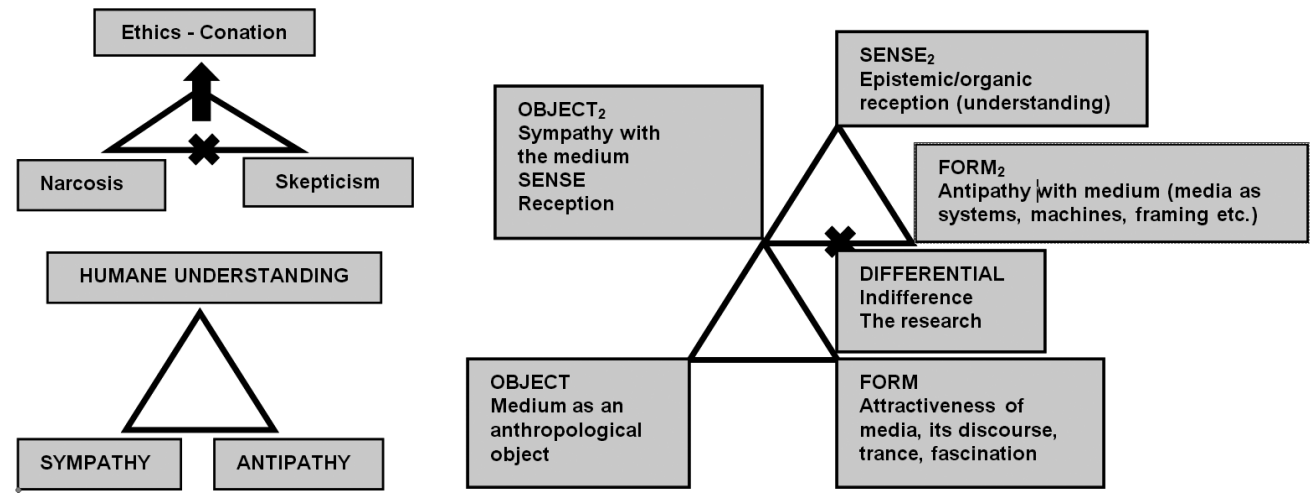

source: author's original illustration

Reception instruction is a phenomenon whose analysis provides manual, apparatus a guide for understanding the relation between myth production activity (at the lowest level of reception) and reviewing competence (at the highest level of reception). Could reception instruction (or a whole reception manual) replace initiation? It is necessary to consider a huge material base, particularly a variety of exotic instructions, but we should respect more principles, including Jakobson's basic functions of language and many theories not only from the field of literary communication and a broader understanding 
of reception (e.g. Miko - Popovič, 1978; Holub, 1984), but also the discourse of media communication and related development of communication theories and models, considering also holistic approach to deformations of media reception and their treatment (e.g. Kosmály, 2011). Logically, in humane reception can hypothetically every humane act or event replaced by other - so humane reception instruction could replace humane initiation, as long as the word "humane" means a recipient's "freedom of choice" (as it used Shannon and Weaver) in media communication. But media as a state of consciousness shall never replace teachers, prophets or shamans as they evolved in human society.

\section{Didactics of words in a global field beyond global village: a project of media therapy}

Didactics epistemic bombastic - this would be the key to doors to reception of media reality, instead of looking through a framed keyhole, finally to open that doors and step into the media reality to co-create it. Let us imagine a priest standing in the field and trying to explain the importance of Slovak Matica (cultural institution) within a dialogue with two peasants - if he wants to convince them of his view, he must use his epistemic competences (so there is Didactics of epistemic competence essential), his ability to mystify (as pastor he has the ethos of the educated person) in order to explain the importance of one Slovak medium. And this whole story takes place in journalistic form as Socratic dialogues of author with readers (Lichard, 1865). By use of literary types (chronotope) he tries to convince the reader medialized in the text as a virtual reader through standardized literary figures and to orient him (reviewing competence is a fundamental reception competence - enables an organic conclusion of reception: metacreation). Daniel Lichard 's model is a model of didactics in the field composed into a text even communicating with the reader and trying to improve his competences. Didactics bombastic expresses therefore the simplicity and accessibility of the "epistemic code" for decoding the message, the true freedom and authenticity of the organic reception system and an understanding survival signs, texts and media. It expresses the beauty of knowing that each recipient is able to "gain back lost or stolen reception competences" built with a variety of receptional reactions to the system of media reality, the joy of acquisition and again manage his own learning and language. It is the exclamation of the Ján Ámos Komenský’s pilgrim who took down his imagination goggles; it is an exclamation of the man who just came out of the Plato cave.

Author of this study yet only twice expressed through a scientific forum the importance of researching media reality, its reception and treating reception deformations: in a study oriented at sensory deprivation/activation in the treatment of reception defects published in 2011 (Kosmály, 2011) and in a conference paper on outline of a media therapy presented in Trnava, Slovakia in 2012. In the dissertation thesis Reception instruction in media reality there are presented several therapeutic ways to treat the distortion of media reception: sensory deprivation (Dark Therapy, Light Pollution and its understanding), sensory activation (a multimedia event) through media substitution (cigarettes through treatment with natural tobacco), organic reception (deconstruction and reconstruction of media and messages), transcendence of the observer and imitation of media - metacreation. 


\section{Conclusion: limits of amputated consciousness}

Is the Light Tourine Shroud of current civilization (Figure 1) - an inverted imprint of artificial light pollution of Earth - a great mirror reflection of our own face as it was in story with Narcis? Are we witnesses of undergoing reception competences because of not-Understanding media and incoming age of destructive consumption? In order to research reception and treatment of its deformation there are many question ranging from sympathy with media to antipathy available. Freedom of choice in media reality is related to the entropy it decreases - the missing knowledge or competence in reception; understanding and a free choice of using or not using media. Media would then as extensions of humane competence mean a redundancy - if competences are deformed or not developed - on the other hand, if e.g. literacy competence would be developed, then also media competences could be formed: critical reading - interpretation, authentic expression, publishing, critical hearing and understanding. Therefore reception instruction can also play the role of information decreasing recipient's entropy and also the role of simulacrum calling the recipient to use it and be a part of it; e.g. light pollution re-explained in the First World artificial night sky brightness atlas (Cinzano - Falchi Elvidge, 2001). So the limits of amputated consciousness may also be its advantages - one can feel free to restore his competences and to make a choice of using certain extensions to be involved in a certain type of media reality (consciousness). Epistemic reception competence is based at own experience and one's methodology for managing or transferring it.

\section{References}

Ajaya, Swami. (2000). Psychoterapie Východu a Západu. Sjednocující paradigma. (Psychotherapy East and West) Praha, Chvojkovo nakladatelství. 194 p.

Cinzano, P - Falchi, F. - Elvidge, C. D. (2001). The first World Atlas of the artificial night sky brightness. [Accessed 05-20-2012] In Monthly Notices of the Royal Astronomical Society, Vol. 328, p. 689-707. Available in Internet http://www.darksky.org/assets/documents/2001 cinzanofirstworldatlas.pdf

Craine, Erin M. Preliminary Experiments Using a Digital Camera to Measure Commercial Light Sources. [Accessed 05-20-2012] Available in Internet http://docs.darksky.org/Reports/GlareMetricExperimentWriteUpFinal.pdf

Earth's City Lights. [Accessed 05-20-2012] Data courtesy Marc Imhoff of NASA GSFC and Christopher Elvidge of NOAA NGDC. Image by Craig Mayhew and Robert Simmon, NASA GSFC. Available in Internet http://visibleearth.nasa.gov/view.php?id=55167

Feyerabend, Paul. (1993). Against Method. First published London: New Left Books, 1975. 3rd Edition published by Verso.

Hall, Stuart. (ed.) (1997). Representation: cultural representations and signifying practices. London - California: Sage. ISBN 0761954325

Heilbrunn, Benoît. (1996). IN SEARCH OF THE HIDDEN GO(O)D. A philosophical deconstruction and narratological revitalization of the eschatological metaphor in marketing. In Brown, Stephen. - Bell, Jim. - Carson, David. (1996). Marketing Apocalypse: Eschatology, Escapology and the Illusion of the End. London, Routledge, p. 111-132. ISBN 9780415148221

Holub, Robert C. (1984). Reception Theory. A Critical Introduction. New York: Methuen. 
Kosmály, Peter. (2011). Multisensory Environment and Sensory Deprivation in the Treatment of Reception Defects. In Creative and Knowledge Society. Bratislava, Paneuropean University in Bratislava, Warsaw, Versita, volume 1, issue 2, p. 96-109.

Lichard, Daniel. (1865). Rozhovory o Matici slovenskej. Banská Bystrica, Matica slovenská.

Merlyn, Vaughan. (2008). The Myth of Information Overload. [Accessed 05-20-2012] Available in Internet http://vaughanmerlyn.com/2008/08/05/the-myth-of-information-overload/

Miko, František - Popovič, Anton. (1978). Tvorba a recepcia. (Creation and reception) Bratislava, Tatran.

Munday, Roderick. (2003). Marshall McLuhan declared that "the medium is the message." What did he mean and does this notion have any value? [Accessed 05-20-2012] Available in Internet http://www.aber.ac.uk/media/Students/ram0202.html

Popovič, Anton et al. (1983). Originál-Preklad. (Original-Translation) Bratislava, Tatran. 368 p.

Shannon, Claude E. - Weaver, Warren. (1964a). The Mathematical Theory of Communication. Tenth printing, USA, The University of Illinois Press. 3 p.

Shannon, Claude E. - Weaver, Warren. (1964b). The Mathematical Theory of Communication. Tenth printing, USA, The University of Illinois Press. 13 p.

Shannon, Claude E. - Weaver, Warren. (1964c). The Mathematical Theory of Communication. Tenth printing, USA, The University of Illinois Press. 56 p.

Shannon, Claude E. - Weaver, Warren. (1964d). The Mathematical Theory of Communication. Tenth printing, USA, The University of Illinois Press. 56 p.

Shannon, Claude E. - Weaver, Warren. (1964e). The Mathematical Theory of Communication. Tenth printing, USA, The University of Illinois Press. 56 p.

Shannon, Claude E. - Weaver, Warren. (1964f). The Mathematical Theory of Communication. Tenth printing, USA, The University of Illinois Press. 14 p.

Shannon, Claude E. - Weaver, Warren. (1964g). The Mathematical Theory of Communication. Tenth printing, USA, The University of Illinois Press. 56-57 p.

Shannon, Claude E. - Weaver, Warren. (1964h). The Mathematical Theory of Communication. Tenth printing, USA, The University of Illinois Press. 28 p.

PhDr. Peter Jan Kosmály,

Nr. 77 Františka Hečku St., 934 01, Levice, SR, +421 914289 679,

peter.kosmaly@gmail.com, Faculty of Massmedia, Pan European University in Bratislava, Tematínska 10, Bratislava, SR 